\title{
DOCUMENTOS
}

\section{La Editorial Sempere en Hispanoamérica y España}

Zum Felde en su Proceso intelectual del Uruguay, habla de las nuevas ideas revolucionarias en arte y política de principios de siglo. Se refiere a su influencia sobre los jóvenes escritores uruguayos:

Una circunstancia especial contribuyó a la difusión y entendimiento de aquellas ideas: los volúmenes de la Editorial Sempere, de Valencia, que traducían al castellano las obras de los escritores revolucionarios de Europa en esos últimos años, vendiéndolas a precios populares. Así se dio curso callejero a libros que, hasta entonces, solo estuvieron reservados a los estudiosos. Stirner, Marx, Proudhon, Nietzsche - los ideólogos tevolucionarios- andaban en todas las manos, llegaban a los hogares más humildes, compartían los más oscuros cuartuchos y se sentaban a las mesas de todos los cafés bohemios. ${ }^{1}$

González Vera recuerda la impresión que le produjo la lectura de las obras de esta biblioteca en sus años juveniles. ${ }^{2}$ Udo Rukser señala la importancia que en la vida intelectual de Hispanoamérica tuvieron aquellos libros:

Am meisten hatte jedoch diese Entwicklung den billigen Ausgabe des Verlages Sempere in Valencia zu danken. Für die Geistes-

1 (Montevideo, 1930), vol. II, 53.

2 J. González Vera, Cuando era muchacho (Santiago de Chile, 1951), 136-137. 
und Bildungsgeschichte Latein Amerikas ist die populäre Bibliothek dieses Verlegers ebenso entscheidend geworden wie für Spanien. Dieser Mann, der die Realitäten des analphabetischen Spaniens kannte und dessen Bedüurfnisse, liep' sich von dem Ideal leiten, Bildung unters Volk zu bringen, etwa mit der Losung "Wissen ist Macht". Dies didaktische Ziel nat nat er unverrückt verfolgt, so da durch ihn in Spanien wie in Latein-Amerika viele wichtige Autoren erstmalig zu haben waren und noch dazu für einen so billigen Preiș, da sie praktisch jeder kaufen konnte: vier Reale kostete das Bändchen, weiniger als eine Mark. ${ }^{3}$

Esta editorial fue fundada por el librero Sempere y pronto contó con la asesoría literaria de Blasco Ibáñez; posteriormente pasó a llamarse Prometeo. Publicó un gran número de traducciones, muchas veces bastante descuidadas, de los principales pensadores "avanzados" europeos del momento, así como obras originales de los jóvenes literarios españoles y americanos.

Nuestras investigaciones en el Archivo de Unamuno en Salamanca nos permitieron localizar el documento que aquí publicamos; es una carta de Sempere a Unamuno, escrita en 1909. El librero le proporciona fechas de publicación y número de ejemplares distribuídos en España y en América de obras que habrían de tener un profundo impacto en todo el mundo de habla española.

Aunque desgraciadamente las cifras de distribución que ofrece para Hispanoamérica son globales, con la excepción de una significativa observación sobre México, la información que nos da este documento es de importancia fundamental. Los datos contenidos en él, son probablemente únicos, por haber sido destruído el archivo de la editorial durante la guerra civil española. A través de ellos se puede documentar la popularidad y acogida de varias figuras europeas clave en un momento crucial de las letras hispánicas. Como los libros de Sempere generalmente aparecían sin fecha de publicación, este escrito nos permite datarlos con toda precisión.

Muchas otras reflexiones se podrían hacer sobre el contenido de esta carta, pero preferimos of recerla a los estudiosos para que ellos mismos saquen sus propias conclusiones:

University of California Berkeley

RAFAel PÉREZ De la DEHESA

${ }^{3}$ Nietzsche in dej Hispania (Munich y Berna, 1962), pp. $40-41$. 


\section{Carta de Sempere a Unamuno}

Valencia 5 de Marzo de 1909

Sr. D. Miguel de Unamuno

Salamanca.

Muy Sr. nuestro, a continuación van los detalles que $V$. se sirvió pedirnos y sólo nos resta repetirnos de V. afmo. S. S.

F. Sempere y Co.

Bakunine,-“Federalismo..." $1^{\text {a }}$ edición Sepbre. de 1905, tirada 6000 ij., segunda edición 4000 --vendidos España 2500 y América 6300 resto en almacén.

Bakunine,-- "Dios y el estado", 1a edición Marzo 1902- tirada 6000, tres ediciones posteriores de 4000 venta España 5300 América 9400.

Barón de Holbach _ "Moisés, Jesús y Mahoma" $1^{\text {a }}$ ed. Sepbre. 1903-, $I^{a}$ edición. 4000 ejes. dos ediciones posteriores de 4000 -venta España 4200. Amer. 6500 .

Büchner,-_"Ciencia y naturaleza" $1^{\text {a }}$ Febrero $1908-6000$ ejes. $2^{\text {a }} 4000$ verta a España 3000 América 4000.

Büchner, "Fuerza y materia", $1^{\text {a }}$ Agosto 1903.-6000 ejes. cuatro ediciones posteriores de 4000 ejes. venta España 7000 América 9000.

Büchner. "Luz y vida", 1 a Dicbre. $1903-6000$ ejes. tres ediciones posteriores de 4000- venta España 6400 América 8000.

Darwin- "Origen del hombre" $1^{\text {a }}$ Agosto 19026000 - posteriores dos de 10000 ejes. una a 16000 dos a 4000 y una a 6000 total 56000 , venta España 22000, América 29000.

Darwin. "Origen de las especies" 3 tomos $1^{\text {a }}$ Abril de 1903-6000, dos 6000 cuatro posteriores a 4000 - venta España 5000 América 6500. Darwin- "Mi viaje altrededor del mundo" 2 tomos, 19 Enero 1903. 4000; dos ediciones posteriores de 4000 y 6000 - venta España 3800 América 5700.

Draper- "Conflictos entre la religión y el dogma" 1", Mayo 1902.6000 cuatro postriores a 4000- venta España 8000 América 10500.

Haeckel "Los enigmas del universo" 2 tomos 1a Enero 1903- 6000 otra 
edición de 4000, ahota reimprimiéndose 4000 venta España 2000 Aca. 8000.

Kropotkine "Conquista del pan" $1^{\text {a }}$ Debre. de 1900- 4000, posteriores tres ediciones de 6000 una de 12000 dos de 8000 total 50000 venta en España 28000 Aca. 22000 hoy agotada vamos a reimprimir 8000.

Kropotkine "Palabras de un rebelde" 1a Marzo 1901- 8000. posteriores dos ediciones de 6000- venta España Aca. 5000.

Kropotkine "Campos, fábricas y talleres" $1^{\text {a }}$ Febrero 1942- 6000 tres ediciones posteriores de 4000 - venta España 6000 América 10500.

Kropotkine "Las prisiones" Mayo 1903- 6000 tres ediciones posteriores de 4000 una de 6000 venta España Aca. 11000.

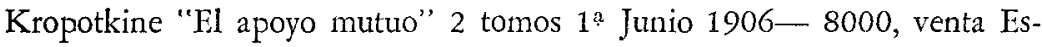
paña 2200 América 4300.

Carlos Marx- "El capital" $1^{\text {n }}$ Nobre. 1903. 8000 cuatro posteriores tres a 4000 una a 6000- venta a España 9000 América 14000.

Max Stirner- "El único y su propiedad" 2 tomos $1^{\text {a }}$ Sepbre. de 19us6000 otra posterior de 4000 venta España 3500 Aca. 4800.

Mazzini.-"Deberes del hombre" 1" Marzo de 1906-600 0 dos postetiores de 4000 venta España 2800 Aca. 7500.

Nietzsche- "Asi hablaba Zaratustra" 1" Octubre de 1906-6000 dos posteriores de 4000 venta España 5000 América 7000.

Nietzsche "Genealogía de la moral" 1 a Octubre 1906- 6000 dos posteriores de 4000- venta España 3000 Aca. 6000.

Nietzsche- "El Antiristo" 1" Nobre. de 1906- 6000 otra de 4000 venta España 2900 América 6000.

Nietzsche- "La gaya ciencia" 1 a Nobre. de 1906- 6000 otra de 4000 venta España 2800 Aca. 5600.

Nietzsche- "El caso Wagner" 1? Debre. 1906- 6000 otra de 4000 venta España 2500 Aca. 5500.

Nietzsche- "Humano demasiado humano" 1 tomo, "El origen de la tragedia" 1 tomo, "Aurora" 1 tomo, "El crepúrculo de los ídolos", 1 tomo, "Más allá del bien y del mal" 1 tomo, "El viajero y su sombra" 1 tomo, todos se publicaron en Dcbre. de 1906 - tirada de 6000 ejemplares, no se han reimpreso venta España aproximadamente 1900 ej. América 3000.

Renán- "Estudios religiosos" mayo 1902- 60005 ediciones posteriores de 6000- venta España 14000 América 16000. 
Renán- "La Iglesia Cristiana" julio 1905 -6000- dos posteriores de 5000- venta España 4000, América 9000.

Renán- "El porvenir de la ciencia" 1" julio 19032 tomos 6000 y otra de 4000- venta España 3000, América 5000.

Renán- "Los Evangelios" 2 tomos octubre 1904-6000 2 ediciones 4000 - venta España 5000 América 6000.

Renán- "El Anticristo" 2 tomos marzo de 1904- 6000- dos ediciones posteriores de 6000, venta España 7000 América 8000.

Renán-. "Marco Aurelio" 2 tomos Enero 1906- 6000 otra de 4000 venta España 3000 América 5000.

Renán- "Averroes y el Averroismo" 2 tomos Octubre 1907, 6000 ej. venta España 1400 América 3700.

D. F. Strauss- "La antigua y la nueva fe" 1a Mayo 1905- 8000 ej. y 2 de 6000- venta España 6000 América 11000.

Strauss- "Estudios literarios" 1 " Nobre. 1905, 8000 y otra de 4000 venta España 3000 América 7500.

Voltaire- "Diccionario filosófico" 6 tomos Febrero 1905. 6000 y dos posteriores de 4000- venta España 6500 América 5900.

Enest Haeckel- "Historia de la creación natural de los seres" 2 tomo; a tres pesetas- Febrero de 19054000 ejemplates. Venta España 1600 América 2000.

Estos son los datos registrados, que pueden contener algún pequeño error, se ha observado que las obras de dos o más volúmenes se venden mucho menos y la venta principal de estas obras es en la América del Sur, en México prefieren las novelas, mas desde el año 1907 que notamos un gran aumento de venta en obras de Sociología o Filosóficas.

Si necesitase 'más datos o estos estuviesen confusos, dándonos más tiempo haríamos una plantilla impresa. 
